\title{
Evaluation of serum vitamin D levels in COVID-19 positive critically ill adults
}

\author{
Ola Alsegai ${ }^{1}$, Kannan Sridharan², Mona Hammad ${ }^{3}$, Mustafa Mohamed Hammad ${ }^{4}$ \\ 1 Associate Professor, Tanta, Egypt \\ 2 Arabian Gulf University, Manama, Bahrain \\ 3 Tanta University, Tanta, Egypt \\ 4 RCSI-MUB, Manama, Bahrain \\ Corresponding author: Ola Alsegai (osegai@health.gov.bh)
}

Received 9 February 2021 Accepted 18 March 2021 Published 20 April 2021

Citation: Alsegai O, Sridharan K, Hammad M, Hammad MM (2021) Evaluation of serum vitamin D levels in COVID-19 positive critically ill adults. Pharmacia 68(2): 347-351. https://doi.org/10.3897/pharmacia.68.e64167

\begin{abstract}
Background: Contradictory evidence exists regarding the association between serum vitamin D levels and the severity and outcomes in coronavirus 2019 (COVID-19) infected patients. We undertook the present study to evaluate the serum vitamin D levels with the other laboratory biomarkers, and the outcomes in our critically ill patients.

Methods: A retrospective observational study was carried out in 58 critically ill adults. Details on their demographics, laboratory parameters such as 25-hydroxy vitamin D [25(OH)D] levels, interleukin-6, serum ferritin, lactate dehydrogenase, creatine kinase (CK), D-dimer, C-reactive protein, fibrinogen, procalcitonin, and erythrocyte sedimentation rate were retrieved. Serum 25(OH)D levels were categorized as follows: $\geq 50 \mathrm{nmol} / \mathrm{L}$ - normal; $30-49$ - insufficient; and $<30 \mathrm{nmol} / \mathrm{L}$ - deficient. Post-hoc, we also compared the outcomes between those with 25(OH)D levels of $80 \mathrm{nmol} / \mathrm{L}$ and above, with those of $<80 \mathrm{nmol} / \mathrm{L}$.

Results: Fifty-eight patients were recruited of which 31 (53.4\%) died. Mean \pm SD serum 25(OH)D levels amongst the study participants were $48.5 \pm 27.7 \mathrm{nmol} / \mathrm{L}$. Twenty-two (37.9\%) individuals had insufficient 25(OH)D levels, and $15(25.9 \%)$ were deficient. Eight (13.8\%) participants had their serum 25(OH)D levels $\geq 80 \mathrm{nmol} / \mathrm{L}$. Median (range) 25(OH)D levels were not significantly different between those who died compared to those alive [41 (20-162) vs. $41(17-86) \mathrm{nmol} / \mathrm{L} ; \mathrm{p}=0.8]$. Significantly higher $\mathrm{D}$-dimer levels were observed amongst those with $<80 \mathrm{nmol} / \mathrm{L}$ serum $25(\mathrm{OH}) \mathrm{D}$ levels. No significant differences were observed between $25(\mathrm{OH}) \mathrm{D}$ and other laboratory biomarkers except for elevated CK in patients with insufficient 25(OH)D levels.

Conclusion: We did not observe any significant differences in the serum 25(OH)D levels amongst our critically ill adults who died and who were alive at the time of their admission.
\end{abstract}

\section{Keywords}

Vitamin D, IL-6, COVID-19, Coronavirus 


\section{Introduction}

\section{Background}

Coronavirus 2019 (COVID-19) resulted in an unprecedented pandemic affecting 96,218,601 patients with a mortality rate of $2,058,534$ at the time of writing this manuscript (COVID-19 dashboard 2021).Vitamin D levels influence the renin-angiotensin system, modulate the cellular and adaptive immunity, and alter the physical barriers to infections, thus playing a vital role in COVID-19 infections (Annweiler et al. 2020). Hypovitaminosis D is also attributed to viral reactivation as well as a slower rate of viral clearance (Zwart and Smith 2020). Hypovitaminosis $\mathrm{D}$ was hypothesized to be a risk factor for the emergence and spread of COVID-19 infections in the northern hemisphere that occurred during winter (Mitchell 2020). A systematic review of nine observational studies revealed that vitamin D levels were significantly associated with the rates of COVID-19 related infections, prognosis, and the associated mortality (Yisak et al. 2021). A study from the United States revealed that vitamin D deficiency increases the risk of COVID-19 infections by four times (Katz et al. 2020). In a study from UK Biobank that included 348,598 participants, after adjusting for the confounders, 25-hydroxyvitamin D [25(OH)D] levels were not associated with COVID-19 infections(Hastie et al 2020). Contradictory evidence exists regarding the association between hypovitaminosis D and the severity of COVID-19 infections and the related mortality.

Ethnicity, cultural practices, latitude, and ultraviolet exposures are some of the core factors influencing vitamin $\mathrm{D}$ levels resulting in huge variations between the countries/continents. Considering the dearth of data from the region, we undertook the present study to evaluate serum vitamin D levels in our critically ill patients with COVID-19 infections.

\section{Methods}

The study was carried out between November 2020 and January 2021 in the Tanta hospital, Egypt. It was a retrospective study amongst critically ill adults with COVID-19 infections whose $25(\mathrm{OH}) \mathrm{D}$ level was assessed at the time of admission. The following details were collected: age, gender, laboratory parameters $[25(\mathrm{OH}) \mathrm{D}$ levels, interleukin-6 (IL-6), serum ferritin, lactate dehydrogenase (LDH), creatine kinase (CK), d-dimer (DD), C-reactive protein (CRP), fibrinogen, procalcitonin, and erythrocyte sedimentation rate (ESR)] and outcome (alive/died). Serum $25(\mathrm{OH}) \mathrm{D}$ levels were categorized as follows: $\geq 50 \mathrm{nmol} / \mathrm{L}$ - normal; 30-49- insufficient; and $<30 \mathrm{nmol} / \mathrm{L}$ - deficient (Amrein et al 2020).Post-hoc, we also categorized serum 25(OH)D levels based on $80 \mathrm{nmol} / \mathrm{L}$ thresholds. The reference ranges for the evaluated biomarkers in our laboratory are as follows: ferritin: $20-282 \mu \mathrm{g} / \mathrm{L}$ in females and $16-323 \mu \mathrm{g} / \mathrm{L}$ in males; CRP: $0-3 \mathrm{mg} / \mathrm{L}$; procalcitonin: 0-0.5 $\mu \mathrm{g} / \mathrm{L} ; 25(\mathrm{OH}) \mathrm{D}: \geq 50 \mathrm{nmol} / \mathrm{L}$; IL-6: <7 pg/ml; LDH:
135-214 IU/L; ESR: <20 mm/hour; CK: 21-215 IU/L; fibrinogen: $217-496 \mathrm{mg} / \mathrm{dl}$; and DD: $0.09-0.33 \mathrm{mg} / \mathrm{L}$.

\section{Estimation of 25(OH)D levels}

Serum 25(OH)D levels were estimated on Siemen's Advia Centaur using the principles of antibody competitive immunoassay that uses an anti-fluorescein monoclonal mouse antibody covalently bound to paramagnetic particles (PMP), an anti- 25(OH)vitamin D monoclonal mouse antibody labeled with acridinium ester (AE), and a vitamin $\mathrm{D}$ analog labeled with fluorescein. The assay range used was $10.5-375 \mathrm{nmol} / \mathrm{L}$.

\section{Statistical analysis}

Descriptive statistics were used for representing the demographic characteristics. Numerical variables were evaluated using either Mann-Whitney U or Kruskal-Wallis H tests. Spearman test was used for assessing the correlations of biomarkers with vitamin D levels. Chi-square tests of association were used for evaluating the categorical variables. A $p$-value of $\leq 0.05$ was considered significant. SPSS (IBM Corp. Released 2020. IBM SPSS Statistics for Windows, Version 27.0. Armonk, NY: IBM Corp.) was used for statistical analysis.

\section{Results \\ Demographics}

Fifty-eight patients were recruited with a mean \pm SD age of $60.7 \pm 14.3$ years. Male: female ratio was $27: 31$. The mean \pm SD hospital length of stay of the study participants was $27.1 \pm 6.3$ days. Thirty-one (53.4\%) died.

\section{Serum 25(OH)D levels}

Mean \pm SD serum 25(OH)D levels amongst the study participants were $48.5 \pm 27.7 \mathrm{nmol} / \mathrm{L}$. Twenty-two (37.9\%) individuals had insufficient 25(OH)D levels, and 15 (25.9\%) were deficient. Median (range) 25(OH)D levels were not significantly different between those who died compared to those alive [41 (20-162) vs. $41(17-86) \mathrm{nmol} / \mathrm{L} ; p=0.8]$. Only eight (13.8\%) participants had their serum $25(\mathrm{OH})$ D levels $\geq 80 \mathrm{nmol} / \mathrm{L}$.

\section{Association between 25(OH)D levels with other biomarkers}

No significant differences were observed in the other biomarker levels between those with normal and deficient 25(OH)D (Table 1). However, those with serum $25(\mathrm{OH}) \mathrm{D}$ levels $<80 \mathrm{nmol} / \mathrm{L}$ had significantly higher serum DD levels compared to those with $\geq 80 \mathrm{nmol} / \mathrm{L}$. Also, patients with insufficient $25(\mathrm{OH}) \mathrm{D}$ levels were observed with a greater proportion of elevated creatine kinase (Figure 1). No significant correlations were ob- 
Table 1. Comparison of the characteristics between individuals with normal, insufficient, and deficient serum 25(OH)D levels.

\begin{tabular}{|c|c|c|c|c|c|c|c|}
\hline Parameters & $\begin{array}{c}\text { Normal vitamin } D \\
\text { levels }(n=21)\end{array}$ & $\begin{array}{c}\text { Insufficient vitamin D } \\
\text { levels }(n=22)\end{array}$ & $\begin{array}{c}\text { Deficient vitamin D } \\
\text { levels }(n=15)\end{array}$ & $p$-values & $\begin{array}{c}\text { Participants with serum } \\
\text { 25(OH)D levels }<80 \\
\text { nmol } / \mathrm{L}(\mathrm{n}=50)\end{array}$ & $\begin{array}{l}\text { Participants with serum } \\
\text { 25(OH)D levels } \geq 80 \\
\text { nmol/L }(\mathrm{n}=8)\end{array}$ & $p$-values \\
\hline Serum IL-6 (pg/ml) & $43(5-195)$ & $46(0.7-5000)$ & $54(14.8-609)$ & 0.9 & $47.6(0.7-5000)$ & $47.7(5-158)$ & 0.7 \\
\hline Serum ferritin $(\mu \mathrm{g} / \mathrm{L})$ & $947.5(85-2054)$ & $565(158-3388)$ & $384(33-6681)$ & 0.4 & $608(33-6681)$ & $397(85-1168)$ & 0.2 \\
\hline Serum LDH (U/L) & $329(144-916)$ & $326(175-850)$ & $313(173-700)$ & 0.8 & $320.5(173-916)$ & $343(144-535)$ & 0.9 \\
\hline Serum creatine kinase $(\mathrm{U} / \mathrm{L})$ & $142(22-573)$ & $308(16-1653)$ & $140(36-432)$ & 0.1 & $187(16-1653)$ & $131.5(34-315)$ & 0.5 \\
\hline Serum D-dimer (mg/L) & $1.1(0.3-8.2)$ & $0.8(0.2-80)$ & $2.3(0.3-19.7)$ & 0.2 & $1.2(0.2-80)$ & $0.6(0.3-1.1)$ & $0.009^{*}$ \\
\hline C-reactive protein $(\mathrm{mg} / \mathrm{L})$ & $63.4(14-192)$ & $53(6.8-366)$ & $94(14.6-293)$ & 0.5 & $81.9(6.8-366)$ & $59.5(53-181)$ & 0.7 \\
\hline Serum fibrinogen (mg/dl) & $385(303-660)$ & $419(177-678)$ & $530(178-761)$ & 0.2 & $451(177-761)$ & $384(304-538)$ & 0.3 \\
\hline Procalcitonin $(\mu \mathrm{g} / \mathrm{L})$ & $0.3(0.04-1.8)$ & $0.4(0.1-12)$ & $0.27(0.01-3.2)$ & 0.2 & $0.3(0.01-12)$ & $0.4(0.04-0.5)$ & 0.9 \\
\hline ESR (mm/hour) & $74(30-123)$ & $32(20-115)$ & $66(5-107)$ & 0.3 & $63(5-123)$ & $44.5(44-45)$ & 0.6 \\
\hline
\end{tabular}

IL-6-Interleukin; LDH-Lactate dehydrogenase; ESR-Erythrocyte sedimentation rate.

60

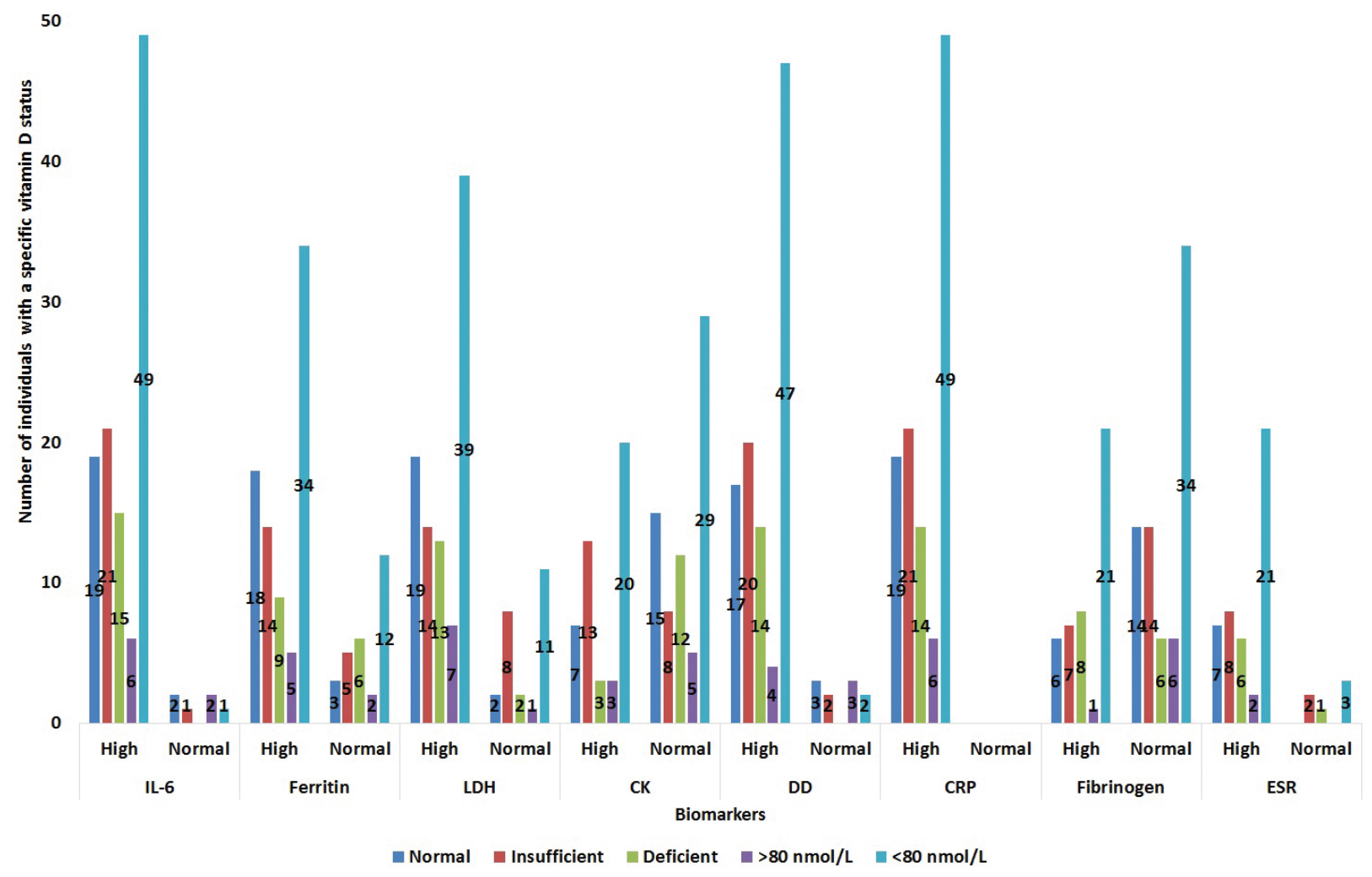

Figure 1. Categories of vitamin D status and other biomarker levels. The bar chart represents the number of patients with a specific vitamin D status and categories of other biomarkers.

served between serum 25(OH)D levels and other biomarkers (Figure 2).

\section{Discussion}

We carried out the present study in 58 critically ill patients with 25(OH)D levels assayed on admission. We did not observe any significant differences in the serum levels of 25(OH)D between those who died and those who are alive. No significant differences were observed with other laboratory biomarkers except for elevated creatine kinase levels in individuals with insufficient 25(OH)D levels and elevated DD levels amongst those with serum 25(OH)D $<80 \mathrm{nmol} / \mathrm{L}$.

Jain et al. in 2020 reported in 154 COVID-19 positive patients of which 63 had severe illness requiring admission in the critical care unit, and 91 were asymptomatic revealed a prevalence of vitamin D deficiency to an extent of 96.82 and $32.96 \%$, respectively. Additionally, the authors observed significantly elevated inflammatory markers such as IL-6, serum ferritin, and tumor necrosis factor-alpha with an increased mortality risk amongst those with hypovitaminosis D. However, we did not observe any such differences that can be possibly explained by the following reasons: measurement of $25(\mathrm{OH}) \mathrm{D}$ levels were 


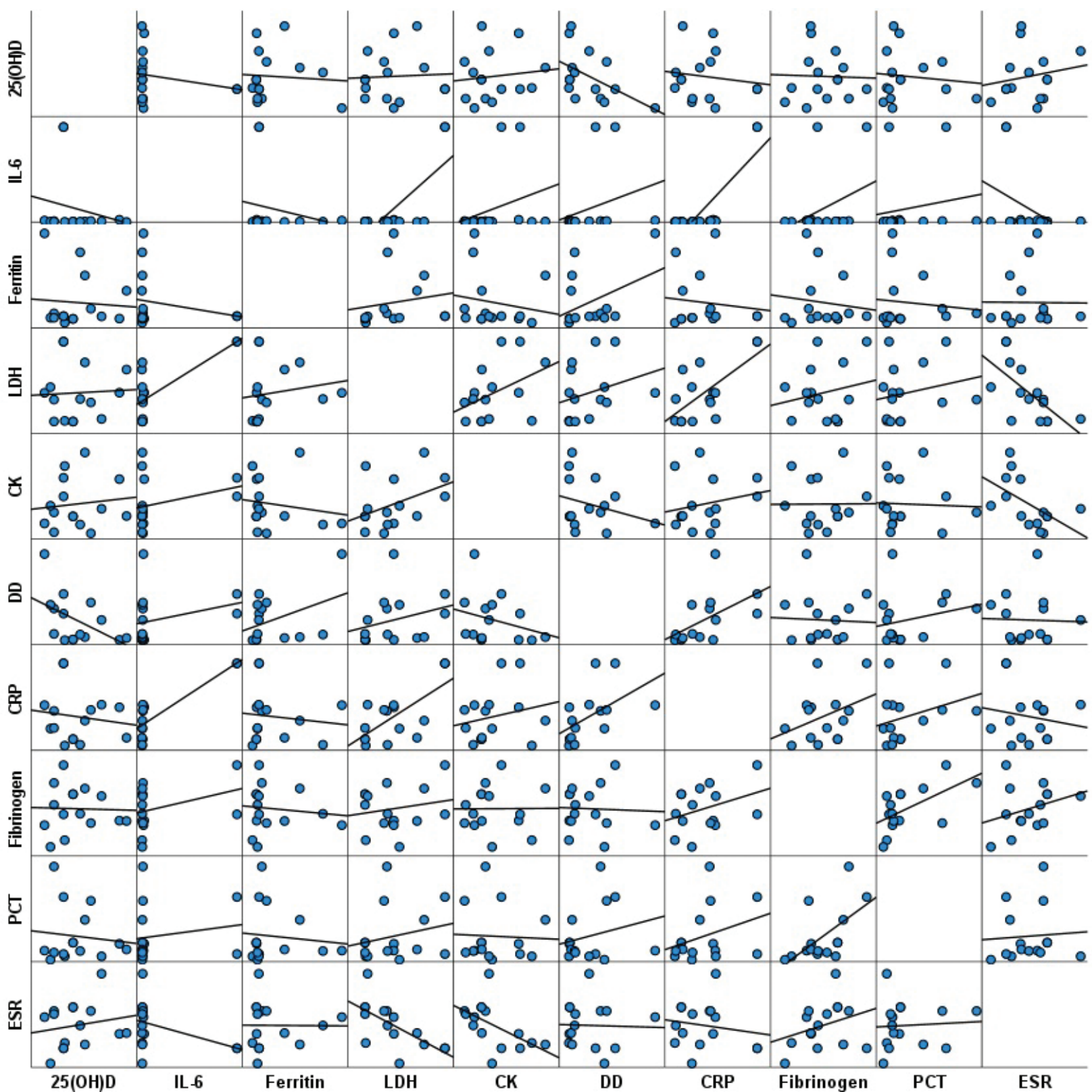

Figure 2. Correlation matrix between serum $25(\mathrm{OH}) \mathrm{D}$ and other biomarkers. 25(OH)D - 25-hydroxy vitamin D; IL-6 - Interleukin-6; LDH - Lactate dehydrogenase; CK - Creatine kinase; DD - D-dimer; CRP - C-reactive protein; PCT - Procalcitonin; ESR - Erythrocyte sedimentation rate.

carried out at the time of admission while it may have reduced when the patient deteriorated; and that the present study was carried out during November until January during which the prevalence of vitamin D deficiency in general, is lower in our region. Studies have explored the potential influence of the latitudinal position of countries on the severity and mortality of COVID-19 infections, but nothing was inconclusive (Whittemore 2020). We observed an inverse relationship between the serum $25(\mathrm{OH}) \mathrm{D}$ levels categories ( $\geq 80$ and $<80 \mathrm{nmol} / \mathrm{L}$ ) with DD levels as in a recent study (Hernandez et al. 2020). This is explained by the acute inflammatory state amongst the critically ill adults where DD increases as an acute phase reactant while serum $25(\mathrm{OH}) \mathrm{D}$ levels decreases, as it is a negative acute phase reactant (Waldon et al. 2013). Hypovitaminosis $\mathrm{D}$ has been associated with myopathy and conse- quently an elevated creatine kinase (Sathasivam 2008). Most of our study participants with deficient 25(OH)D levels were observed with chronic hypovitaminosis D and so we observed an elevated creatine kinase in these participants. Furthermore, the present study did not consider the co-morbidities that might have been related to the severity and death of infection in the study participants and we did not have a comparator group. We are also limited by the small sample size.

\section{Conclusion}

We did not observe any significant differences in the serum $25(\mathrm{OH}) \mathrm{D}$ levels in our critically ill patients who died and who were alive at the time of their admission. 


\section{References}

Amrein K, Scherkl M, Hoffmann M, Neuwersch-Sommeregger S, Köstenberger M, Tmava Berisha A, Martucci G, Pilz S, Malle O (2020) Vitamin D deficiency 2.0: an update on the current status worldwide. European Journal of Clinical Nutrition 74: 1498-1513. https://doi.org/10.1038/s41430-020-0558-y

Annweiler C, Cao Z, Sabatier JM (2020) Point of view: Should COVID-19 patients be supplemented with vitamin D? Maturitas 140: 24-26. https://doi.org/10.1016/j.maturitas.2020.06.003

COVID-19 dashboard by the Centre for Systems Science and Engineering at John Hopkins University (2021) COVID-19 dashboard by the Centre for Systems Science and Engineering at John Hopkins University. https://coronavirus.jhu.edu/map.html [Accessed on 20 Jan 2021]

Hastie CE, Mackay DF, Ho F, Celis-Morales CA, Katikireddi SV, Niedzwiedz CL, Jani BD, Welsh P, Mair FS, Gray SR, O’Donnell CA, Gill JM, Sattar N, Pell JP (2020) Vitamin D concentrations and COVID-19 infection in UK Biobank. Diabetology \& Metabolic Syndrome 14(4): 561-565. https://doi.org/10.1016/j.dsx.2020.04.050

Jain A, Chaurasia R, Sengar NS, Singh M, Mahor S, Narain S (2020) Analysis of vitamin D level among asymptomatic and critically ill COVID-19 patients and its correlation with inflammatory markers. Scientific Reports 10: e20191. https://doi.org/10.1038/s41598-02077093-Z

Hernández JL, Nan D, Fernandez-Ayala M, García-Unzueta M, Hernández-Hernández MA, López-Hoyos M, Muñoz-Cacho P, Olmos JM, Gutiérrez-Cuadra M, Ruiz-Cubillán JJ, Crespo J, Martínez-Taboada
VM (2020) Vitamin D Status in Hospitalized Patients with SARSCoV-2 Infection. The Journal of Clinical Endocrinology \& Metabolism 106(3): e1343-e1353. https://doi.org/10.1210/clinem/dgaa733

Katz J, Yue S, Xue W (2020) Increased risk for COVID-19 in patients with vitamin D deficiency. Nutrition 84: e111106. https://doi. org/10.1016/j.nut.2020.111106

Mitchell F (2020) Vitamin-D and COVID-19: do deficient risk a poorer outcome? Lancet Diabetes Endocrinology 8(7): e570. https://doi. org/10.1016/S2213-8587(20)30183-2

Sathasivam S (2008) Statins, myopathy, creatine kinase and vitamin D. BMJ 337: a2286. https://doi.org/10.1136/bmj.a2286

Waldron JL, Ashby HL, Cornes MP, Bechervaise J, Razavi C, Thomas OL, Chugh S, Deshpande S, Ford C, Gama R (2013) Vitamin D: a negative acute phase reactant. Journal of Clinical Pathology 66(7): 620-622. https://doi.org/10.1136/jclinpath-2012-201301

Whittemore PB (2020) COVID-19 fatalities, latitude, sunlight, and vitamin D. American Journal of Infection Control 48(9): 1042-1044. https://doi.org/10.1016/j.ajic.2020.06.193

Yisak H, Ewunetei A, Kefale B, Mamuye M, Teshome F, Ambaw B, Yideg Yitbarek G (2021) Effects of Vitamin D on COVID-19 Infection and Prognosis: A Systematic Review. Risk Management and Healthcare Policy 14: 31-38. https://doi.org/10.2147/RMHP.S291584

Zwart SR, Smith SM (2020) Vitamin D and COVID-19: Lessons from Spaceflight Analogs. The Journal of Nutrition 150: 2624-2627. https://doi.org/10.1093/jn/nxaa233 